\title{
The effect of core formation on vanadium isotopic compositions of the mantle of rocky planets
}

\author{
S. Y. ZHANG ${ }^{1}$, H. L. ZHANG ${ }^{1,2}$, W. $\mathrm{LV}^{1}$, R. BAI ${ }^{1}, \mathrm{X}$,
}

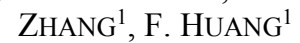

${ }^{1}$ School of Earth and Space Sciences, USTC, Hefei, Anhui, 230026, China

${ }^{2}$ State Key Laboratory of Geological Processes and Mineral Resources, China University of Geosciences, Beijing, China

Core formation is one of the most important events in the history of formation and evolution of rocky planets, which are still challenging to be constrained. Vanadium (V) is slightly siderophile during core-mantle segregation and $\mathrm{V}$ isotopes may have the potential to trace the core formation process if $\mathrm{V}$ isotopes can be fractionated between metallic and silicate melts. Recent studies have revealed a substantially heavier $\mathrm{V}$ isotopic composition (reported as $\delta^{51} \mathrm{~V}=1000 \times\left[{ }^{51} \mathrm{~V} /{ }^{50} \mathrm{~V}_{\text {sample }} /{ }^{51} \mathrm{~V} /{ }^{50} \mathrm{~V}_{\mathrm{AA}}\right.$ )$1] \%$ ) of the bulk silicate Earth (BSE) than the chondrites (preirradiation values) by $0.15 \%[1,2]$, which may be a core formation signature. However, experimental studies suggested no resolvable $\mathrm{V}$ isotope fractionation between pure $\mathrm{Fe}$ and $\mathrm{An}_{50} \mathrm{Di}_{28} \mathrm{Fo}_{22}$ silicate melts at $1.5 \mathrm{GPa}$ and $1650{ }^{\circ} \mathrm{C}$ [3].

Because the existing experiments were performed without considering the effect of minor elements in the core on $\mathrm{V}$ isotope fractionation, here we experimentally determined $\mathrm{V}$ isotope fractionation between metallic and basaltic melts, with particular focus on the effect of $\mathrm{C}, \mathrm{S}$, and $\mathrm{Ni}$ in metallic melts. Experiments were performed at $1 \mathrm{GPa}, 1600^{\circ} \mathrm{C}$ using a 3/4" end-loaded piston cylinder. The isotope equilibrium was assessed using time-series experiments combined with the reverse reaction method. We found that $\mathrm{C}$ and $\mathrm{S}$ contents in the metal do not affect $\mathrm{V}$ isotope fractionation, but increasing Ni content in the metal significantly increases the fractionation. Metallic melts containing $\mathrm{Ni}$ preferentially sequester the light $\mathrm{V}$ isotope $\left({ }^{50} \mathrm{~V}\right)$. Our experiments revealed that $\Delta^{51} \mathrm{~V}_{\text {silicate-metal }}$ is $0.10 \pm 0.03 \%$ at $1 \mathrm{GPa}, 1600{ }^{\circ} \mathrm{C}$ and about $6 \% \mathrm{Ni}$ in the metal. The results suggest that core formation will leave the planetary mantle with slightly heavier $\mathrm{V}$ isotopic composition compared to chondrites.

[1] Qi et al., 2019. GCA 259, 288-301. [2] Hopkins et al., 2019. EPSL 511, 12-24. [3] Nielsen et al., 2014. EPSL 389, 167-175. 